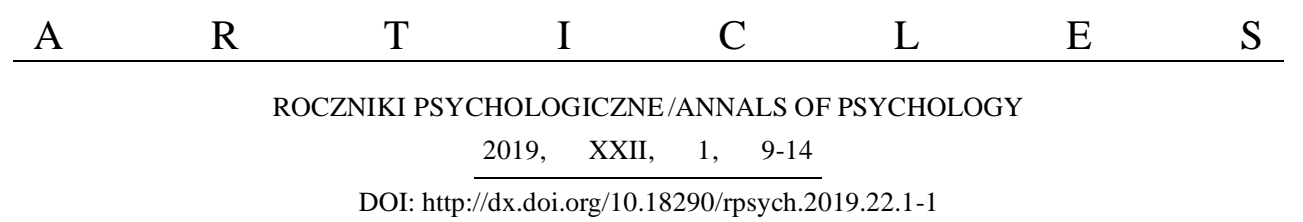

MONIKA WRÓBEL ${ }^{\mathrm{a}}$

MICHAŁ OLSZANOWSKI ${ }^{\mathrm{b}}$

${ }^{a}$ University of Lodz, Institute of Psychology, Poland

${ }^{\mathrm{b}}$ SWPS University of Social Sciences and Humanities in Warsaw, Poland

\title{
EMOTIONS ARE NOT A PRIVATE MATTER: INTRODUCTION TO A SPECIAL ISSUE ON EMOTIONS IN INTERPERSONAL RELATIONSHIPS
}

\begin{abstract}
Although emotions are frequently treated as highly intimate experiences, much empirical evidence indicates that they primarily play interpersonal functions. Here, we briefly review this evidence and argue that the relationship between emotions and social interactions may be bi-directional (that is, emotions may both influence and be influenced by social factors). The papers included in this special issue illustrate this bidirectionality with examples coming from studies on social judgments, emotional contagion, emotional regulation, empathy, and emotion vocalization. Taken together, these papers show that emotions and interpersonal relationships are inextricably intertwined.
\end{abstract}

Keywords: emotion; emotional expression; interpersonal relationships; social functional approach; social interaction.

\section{Emotions are not a private matter:}

\section{Introduction to a special issue on emotions in interpersonal relationships}

Emotions may seem to be very intimate, private experiences. For instance, people often feel uncomfortable when others see them cry, burst with anger, or

Corresponding author: MONIKA WRÓBEL - University of Lodz, Institute of Psychology, ul. Smugowa 10/12, 91-433 Łódź, Poland; e-mail: monika.wrobel@uni.lodz.pl

The preparation of this article and editorial work on this issue was supported by the Polish National Science Centre Grants 2017/26/E/HS6/00725 (to M. Wróbel) and 2016/21/HS6/01179 (to M. Olszanowski). We would like to thank the authors who contributed to this issue and the reviewers, whose comments substantially added to the quality of the papers. 
experience anxiety. Therefore, they sometimes conceal their feelings in order not to appear weak, irrational, or unstable (Tamir, 2016). At the same time, the tendency to hide one's feelings suggests that people are aware that their emotions are powerful messages that, when sent to others, may influence what those others think or how they behave. This tendency thus clearly challenges the assumption that emotions are a private matter and indicates that they are deeply embedded in social interactions.

The idea that emotions evolved to serve interpersonal functions is rooted in the social functional approach to emotions (Keltner \& Haidt, 1999, 2001; Parkinson, 1996; van Kleef, Cheshin, Fischer, \& Schneider, 2016). The approach holds that emotions are social rather than individual phenomena because their primary function is to coordinate social interactions. Much empirical evidence supports this notion by showing that the link between emotions and social interactions may be bi-directional, which means that emotions and emotional-related processes may shape and be shaped by interpersonal relationships.

These two directions are complementary and together define the socioemotional nature of human beings. The first direction indicates that emotions may influence and regulate social interactions by providing information about the expresser's feelings, thoughts, or beliefs (Fischer \& Manstead, 2008; Keltner \& Haidt, 1999; van Kleef, 2009). A growing body of research demonstrates that emotional expressions are frequently treated by observers as indicative not only of the expresser's subjective emotional experience but also of his/her traits or intentions (Crivelli \& Fridlund, 2018; Hareli, Shomrat, \& Hess, 2009; Hareli, David, \& Hess, 2016; Knutson, 1996). For instance, a smiling person is typically perceived as having affiliative intents, whereas a frowning person is frequently seen as having non-affiliative intents (Hareli et al., 2016). This suggests that information gleaned from the emotional expressions of others may affect observers' cognitions, attitudes, and behaviors and, as a result, produce interpersonal effects (van Kleef, 2009; van Kleef, van Doorn, Heerdink, \& Koning, 2011). For instance, people may tend to initiate and maintain social relationships with those who smile and avoid contacts with those who express non-affiliative emotions. Emotions thus have a profound impact on social interactions by either strengthening relationships with others or keeping others at a distance (Fischer \& Manstead, 2008). A good example here are processes responsible for sharing emotions between people, such as emotional mimicry and emotional contagion (i.e., processes by which the emotions of the expresser are imitated and "caught" by the observer). Such processes have been shown to facilitate communication and reinforce social bonds (for a review, see Hess \& Fischer, 2013). At the same 
time, evidence has accumulated that that they are more likely to occur in response to emotional displays that inform about the affiliative intents of the expresser (e.g., happiness) rather than emotional displays that signal antagonism (e.g., anger or disgust) (Hess \& Fischer, 2013; Fischer \& Hess, 2017). This suggests that some emotions may be more critical for fostering social bonds than others (Fischer \& Manstead, 2008).

The second direction highlights the fact that interpersonal relationships may shape the way people experience, express, or regulate their emotions. In general, social interactions are one of the most common causes of emotion (Shaver, Wu \& Schwartz, 1992). The importance of interpersonal factors in emotion causation results from the fact that individuals attach great significance to their relationships with others and thus get emotional about things that relate to other people (Parkinson, 1996). Social relationships also affect the degree to which emotions are expressed. For instance, people are more likely to openly express what they feel in the presence of their friends than in the presence of strangers (Wagner \& Smith, 1991; Smoski \& Bachorowski, 2003). This shows that emotional expressions are highly sensitive to changes in social context and supports the notion that emotional displays are social signals rather than simple reflections of individuals' internal states (Fridlund, 1994). In a similar vein, studies on the two processes mentioned above - emotional mimicry and emotional contagion demonstrate that the tendency to share the emotions of others varies across social interactions. Specifically, both emotional mimicry and emotional contagion have been shown to occur particularly when the relationship between the observer and the expresser is positive, for example when they are closely related or similar to each other (for reviews, see Hess \& Fischer, 2013; Wróbel \& Imbir, 2019). This can be explained by the fact that emotional expressions may carry different meanings depending on the relationship between the interacting partners. For instance, although a smile in itself is an affiliative social signal, its meaning dramatically changes to non-affiliative when it is shown by an enemy or a dislikeable person (e.g., Bourgeois \& Hess, 2008; Wróbel \& Królewiak, 2017). In consequence, in some types of interactions, even intrinsically affiliative emotions may serve a distancing function rather than strengthen the relationship between the expresser and the observer (Fischer \& Manstead, 2008).

Overall, emotions are essentially social phenomena. The aim of this special issue is to bring together papers that share this assumption and focus on emotions and emotion-related processes that are crucial for interpersonal relationships. One of such processes is communication of emotion through nonverbal channels. Although research in this area has been focused on facial expressions, a growing 
number of studies demonstrates that vocal expression of emotions is also a fundamental aspect of interpersonal communication (Bachorowski, 1999; Scherer, Johnstone, \& Klasmeyer, 2003). The paper by Hekiert and Igras-Cybulska (2019, pp. 15-34) reviews theories and methodologies that concern emotional vocalizations in the fields of psychology and digital signal processing. As underlined by the authors, such an integrative approach could be potentially beneficial for both of these fields: Psychological studies could be advanced by improving the parameters of emotional stimuli, while digital sound processing engineering could get deeper insight into discrete and dimensional models of emotions that are used in automatic speech recognition or production.

The social nature of emotions is also demonstrated by their influence on social judgments. Olszanowski, Parzuchowski, and Szymków (2019, pp. 35-52) investigate the interplay between physical facial features and smile by analyzing their combined influence on social judgments. Two studies reported by the authors show that facial features that signal trust affect judgments of trustworthiness to a higher degree than emotional expressions. At the same time, emotional expressions seem to be more crucial than facial features for judgments of dominance.

Szczygieł and Baryła (2019, pp. 53-71) investigate the effects of negative emotional stimulus intensity on the choice of emotion regulation strategy. The authors manipulated the intensity of emotional stimuli by using images eliciting negative emotions of high and low intensity. Next, they tested whether this manipulation would influence the tendency to use reappraisal versus suppression. Notably, such choice may have profound interpersonal consequences because the tendency to use some strategies (e.g., suppression) over others (e.g., reappraisal) is associated with poorer quality of social relationships. Two studies reported by the authors demonstrate that individuals prefer reappraisal over suppression when confronted with low-intensity stimuli but the pattern is the opposite for high-intensity stimuli.

The last two papers focus on emotion sharing. Łada and Kaźmierczak (2019, pp. 73-90) address the role of empathy in the link between negative arousability and relationship satisfaction. The authors highlight the importance of empathy for close relationships by demonstrating that the destructive effects of negative arousability (i.e., sensitivity to negative emotional stimuli) on relationship satisfaction may be cushioned by being more compassionate and caring towards one's partner.

Emotion sharing is also central for Wróbel and Olszanowski (2019, pp. 91-102), whose paper introduces a new method to elicit emotional contagion. 
Drawing on studies on emotional mimicry and addressing the limitations of the methods used in previous studies, the authors created a set of dynamic morphed facial expressions of happiness, sadness, and anger and tested the effectiveness of this set in inducing corresponding emotions in viewers. The results show that the new method effectively induces emotional contagion and thus, provides a good foundation for future research on emotions in social interactions.

Taken together, all papers included in the special issue provide new insights into how deeply emotions and emotion-related processes are weaved into interpersonal relationships. This shows that although emotions are typically experienced as internal, personal reactions, their functions depend crucially on social factors and thus should be studied not only from individual but also from interpersonal perspective. We believe that future research in this area would benefit from continuing this approach.

\section{REFERENCES}

Bachorowski, J.-A. (1999). Vocal expression and perception of emotion. Current Directions in Psychological Science, 8, 53-57. DOI: 10.1111/1467-8721.00013

Bourgeois, P., \& Hess, U. (2008). The impact of social context on mimicry. Biological Psychology, 77, 343-352. DOI: 10.1016/j.biopsycho.2007.11.008

Crivelli, C., \& Fridlund, A. J. (2018). Facial displays are tools for social influence. Trends in Cognitive Sciences, 22, 388-399. DOI: 10.1016/j.tics.2018.02.006

Fischer, A., \& Hess, U. (2017). Mimicking emotions. Current Opinion in Psychology, 17, 151-155. DOI: $10.1016 /$ j.copsyc.2017.07.008

Fischer, A. H., \& Manstead, A. S. R. (2008). Social functions of emotion and emotion regulation. In M. Lewis, J. Haviland, \& L. Feldman Barrett (Eds.), Handbook of emotion ( $3^{\text {rd }}$ edition) (pp. 456-468). New York, NY, US: Guilford Press.

Fridlund, A. J. (1994). Human facial expression: An evolutionary view. San Diego, CA: Academic Press.

Hareli, S., David, S., \& Hess, U. (2016). The role of emotion transition for the perception of social dominance and affiliation. Cognition and Emotion, 30, 1260-1270. DOI: 10.1080/02699931. 2015.1056107

Hareli, S., Shomrat, N., \& Hess, U. (2009). Emotional versus neutral expressions and perceptions of social dominance and submissiveness. Emotion, 9, 378-384. DOI: 10.1037/a0015958

Hekiert, D., \& Igras-Cybulska, M. (2019). Capturing emotions in voice: A comparative analysis of methodologies in psychology and digital signal processing. Roczniki Psychologiczne, 22(1), 15-34. DOI: 10.18290/rpsych.2019.22.1-2

Hess, U., \& Fischer, A. (2013). Emotional mimicry as social regulation. Personality and Social Psychology Review, 17, 142-157. DOI: 10.1177/1088868312472607

Keltner, D., \& Haidt, J. (1999). Social functions of emotions at four levels of analysis. Cognition and Emotion, 13, 505-521. DOI: 10.1080/026999399379168 
Keltner, D., \& Haidt, J. (2001). Social functions of emotions. In T. Mayne \& G. A. Bonanno (Eds.), Emotions: Current issues and future directions (pp. 192-213). New York, NY, US: Guilford Press.

Knutson, B. (1996). Facial expressions of emotion influence interpersonal trait inferences. Journal of Nonverbal Behavior, 20, 165-182. DOI: 10.1007/BF02281954

Łada, A. B., \& Kaźmierczak, M. (2019). Negative arousability and relationship satisfaction: The mediating role of empathy. Roczniki Psychologiczne, 22(1), 73-90. DOI: 10.18290/rpsych. 2019.22.1-5

Olszanowski, M., Parzuchowski, M., \& Szymków, A. (2019). When the smile is not enough: The interactive role of smiling and facial characteristics in making judgments about perceived trustworthiness and dominance. Roczniki Psychologiczne, 22(1), 35-52. DOI: 10.18290/ rpsych.2019.22.1-3

Parkinson, B. (1996). Emotions are social. British Journal of Psychology, 87, 663-683. DOI: 10.1111/j.2044-8295.1996.tb02615.x

Scherer, K. R., Johnstone, T., \& Klasmeyer, G. (2003). Vocal expression of emotion. In R. J. Davidson, K. R. Scherer, \& H. H. Goldsmith (Eds.), Series in affective science. Handbook of affective sciences (pp. 433-456). New York, NY, US: Oxford University Press.

Shaver, P. R., Wu, S., \& Schwartz, J. C. (1992). Cross-cultural similarities and differences in emotion and its representation: A prototype approach. In M. S. Clark (Ed.), Review of personality and social psychology (vol. 3, pp. 175-212). Newbury Park, CA, US: Sage.

Smoski, M., \& Bachorowski J.-A. (2003). Antiphonal laughter between friends and strangers. Cognition and Emotion, 17, 327-340. DOI: 10.1080/02699930302296

Szczygieł, D., \& Baryła, W. (2019). Choosing between emotion regulation strategies to appear cool, calm and collected: Does emotional stimulus intensity matter? Roczniki Psychologiczne, 22(1), 53-71. DOI: 10.18290/rpsych.2019.22.1-4

Tamir, M. (2016). Why do people regulate their emotions? A taxonomy of motives in emotion regulation. Personality and Social Psychology Review, 20, 199-222. DOI: 10.1177/108886 8315586325

Van Kleef, G. A. (2009). How emotions regulate social life: The emotions as social information (EASI) model. Current Directions in Psychological Science, 18, 184-188. DOI: 10.1111/j.1467-8721.2009.01633.x

Van Kleef, G. A., Cheshin, A., Fischer, A. H., \& Schneider, I. K. (2016). Editorial: The social nature of emotions. Frontiers of Psychology, 7, 896. DOI: 10.3389/fpsyg.2016.00896

Van Kleef, G. A., Van Doorn, E. A., Heerdink, M. W., \& Koning, L. F. (2011). Emotion is for influence. European Review of Social Psychology, 22, 114-163. DOI: 10.1080/10463283. 2011.627192

Wagner, H. L., \& Smith, J. (1991). Facial expression in the presence of friends and strangers. Journal of Nonverbal Behavior, 15, 201-214. DOI: 10.1007/BF00986922

Wróbel, M., \& Imbir, K. (2019). Broadening the perspective on emotional contagion and emotional mimicry: The correction hypothesis. Perspectives on Psychological Science, 14, 437-451. DOI: $10.1177 / 1745691618808523$

Wróbel, M., \& Królewiak, K. (2017). Do we feel the same way if we think the same way? Shared attitudes and the social induction of affect. Basic and Applied Social Psychology, 39, 19-37. DOI: 0.1080/01973533.2016.1227709

Wróbel, M., \& Olszanowski, M. (2019). Emotional reactions to dynamic morphed facial expressions: A new method to induce emotional contagion. Roczniki Psychologiczne, 22(1), 91-102. DOI: $10.18290 /$ rpsych.2019.22.1-6 